\title{
Asymptotic synchronization of fractional order non-identical complex dynamical networks with Parameter Uncertainties
}

\author{
S Aadhithiyan ${ }^{1}$, R. Raja ${ }^{1}$, Bo Kou ${ }^{2}$, G Selvam³ ${ }^{3}$ Michal Niezabitowski ${ }^{4}$, C.P Lim ${ }^{5}$, and \\ Jinde $\mathrm{CaO}^{2}$
}

\author{
${ }^{1}$ Alagappa University \\ ${ }^{2}$ Southeast University \\ ${ }^{3}$ Vinayaka Missions University \\ ${ }^{4}$ Silesian University of Technology \\ ${ }^{5}$ Deakin University
}

March 14, 2021

\begin{abstract}
This article specically deals with the asymptotic synchronization of non-identical complex dynamic fractional order networks with uncertainty. Initially, by using the Riemann-Liouville derivative, we developed a model for the general non-identical complex network, and based on the properties of fractional order calculus and the direct Lyapunov method in fractional order, we proposed that drive and response system if nonidentical complex networks ensuring asymp-totic synchronization by using neoteric control. Second, taking into account the uncertainties of non-identical complex networks in state matrices and evaluating theirrequirements forasymptotic synchronization. In addition, to explain the eectiveness of the proposed approach, two numerical simulations are given.
\end{abstract}

\section{Hosted file}

fractionalnonidentical paper.pdf available at https://authorea.com/users/401421/articles/ 513490-asymptotic-synchronization-of-fractional-order-non-identical-complex-dynamicalnetworks-with-parameter-uncertainties 